\title{
Pandemic influenza preparedness in the WHO African region: are we ready yet?
}

\author{
Evanson Z. Sambala ${ }^{1 *}\left(\mathbb{D}\right.$, Tiwonge Kanyenda ${ }^{2}$, Chinwe Juliana Iwu ${ }^{1,3}$, Chidozie Declan Iwu ${ }^{4}$, Anelisa Jaca ${ }^{1}$ \\ and Charles S. Wiysonge ${ }^{1,5,6}$
}

\begin{abstract}
Background: Prior to the 2009 pandemic H1N1, and the unprecedented outbreak of Highly Pathogenic Avian Influenza (HPAl) caused by the H5N1 virus, the World Health Organization (WHO) called upon its Member States to develop preparedness plans in response to a new pandemic in humans. The WHO Member States responded to this call by developing national pandemic plans in accordance with the International Health Regulations (IHR) to strengthen the capabilities of Member States to respond to different pandemic scenarios. In this study, we aim to evaluate the quality of the preparedness plans in the WHO African region since their inception in 2005.

Methods: A standard checklist with 61 binary indicators ("yes" or "no") was used to assess the quality of the preparedness plans. The checklist was categorised across seven thematic areas of preparedness: preparation (16 indicators); coordination and partnership (5 indicators); risk communication (8 indicators); surveillance and monitoring (7 indicators); prevention and containment (10 indicators); case investigation and treatment (10 indicators) and ethical consideration (5 indicators). Four assessors independently scored the plans against the checklist.
\end{abstract}

Results: Of the 47 countries in the WHO African region, a total of 35 national pandemic plans were evaluated. The composite score for the completeness of the pandemic plans across the 35 countries was $36 \%$. Country-specific scores on each of the thematic indicators for pandemic plan completeness varied, ranging from 5\% in Côte d'Ivoire to 79\% in South Africa. On average, preparation and risk communication scored 48\%, respectively, while coordination and partnership scored the highest with an aggregate score of $49 \%$. Surveillance and monitoring scored 34\%, while prevention and containment scored 35\%. Case investigation and treatment scored 25\%, and ethical consideration scored the lowest of $14 \%$ across 35 countries. Overall, our assessment shows that pandemic preparedness plans across the WHO African region are inadequate.

Conclusions: Moving forward, these plans must address the gaps identified in this study and demonstrate clarity in their goals that are achievable through drills, simulations and tabletop exercises.

Keywords: National preparedness plans, Pandemic influenza, Africa, Quality of the plans, Surveillance, Containment, Communication, Ethical framework, Treatment

\section{Background}

Pandemic influenza is a rare disease caused by a novel influenza virus, a subtype that has the capability to cause sustained human-to-human transmission and to which the population has no or little immunity [1]. Historically, there have been 31 possible influenza outbreaks since 1580 , occurring approximately once every 15 years [2],

\footnotetext{
* Correspondence: Evanson.Sambala@mrc.ac.za

${ }^{1}$ Cochrane South Africa, South African Medical Research Council, Box 19070,

Cape Town, PO 7505, South Africa

Full list of author information is available at the end of the article
}

with 3 occurring in the twentieth century: the outbreaks of 1918, 1957, and 1968. The 1918 pandemic influenza outbreak was the most devastating, causing between 50 and 100 million deaths worldwide [3]. In Africa, the pandemic influenza fatality count was 2.3 million deaths, which is deemed to be underreported [4]. The 1957 and 1968 pandemic influenza in Africa caused about 2-3 million and 1 million excess deaths, respectively [5]. In the twenty-first century, an influenza pandemic occurred in 2009 causing 18,156 deaths globally [6].

(c) The Author(s). 2018 Open Access This article is distributed under the terms of the Creative Commons Attribution 4.0 International License (http://creativecommons.org/licenses/by/4.0/), which permits unrestricted use, distribution, and 
The highly pathogenic avian influenza (H5N1) does not usually infect humans, but poses a great threat in spillover from animal to human population, often with fatal outcomes when humans are infected. Between 1990 and 2000, avian virus H5N1 actively circulated uninterrupted among migratory birds and animals in Asia, Europe and Mediterranean, thus giving the prospects for a serious influenza pandemic outbreak in humans [7].

Following these threats and the anticipation of another pandemic, the World Health Organization (WHO) requested Member States to develop preparedness pandemic plans to ensure countries are equipped to mitigate the challenges a pandemic would present. This call was timely, given the limitations of the existing global influenza surveillance and monitoring system to respond, deploy and implement activities to mitigate the impact of an outbreak [8].

In 1999, the WHO published the first guiding principles for pandemic influenza preparedness [8]. These guidelines subsequently underwent revisions in 2005 and 2009, incorporating the practical outbreak response experiences gained from outbreaks of avian $\mathrm{H} 5 \mathrm{~N} 1$ and 2009 H1N1 influenza [9, 10]. These guidelines provide a framework for organising preparedness and response actions. The WHO recommends that, as Member States develop or update their national plans, they should consider the proposed phases in the context of country-specific needs, priorities and actions.

Based on the WHO resolution issued in April 2005 [11], many countries in Africa drafted their national plans between 2005 and 2007, and subsequently used the plans to respond to the $2009 \mathrm{H} 1 \mathrm{~N} 1$ pandemic influenza. However, there is insufficient information on how the preparedness plans were utilized during the 2009 H1N1 pandemic and the lessons that were drawn to improve responses to the next pandemic. Furthermore, since the inception of these plans into action, no study has evaluated the quality of 2009 post pandemic preparedness plans in the WHO African region. The purpose of this present study was to evaluate the completeness of the preparedness plans. We postulated that planning for a pandemic influenza is only as satisfactory as the assumptions on which they are proposed; thus studying them is necessary. Findings from this study will be used to highlight areas of the plans that need strengthening and improvement.

\section{Methods}

We searched the electronic databases of the WHO and United Nations (UN) plus grey literature for the availability of the national pandemic influenza preparedness plans from the WHO African region that were published between 2005 and 2017. In instances where the plans were not available online, we contacted the Ministries of Health in the respective countries for their plans. We considered countries that had plans for avian or human influenza, or both. We excluded plans that were not in public domain. Pandemic influenza plans are a blueprint for managing the emergency outbreak and, as such, should be shared with citizens and stakeholders to inform them about their roles and responsibilities in responding to a possible threat [12].

We translated plans written in French into English using google translation software. Where two national plans for a country were available, we read, assessed and treated both the draft and updated version of the plan as a unit. Four assessors (TK, CJI, CDI and AJ) independently read and scored the plans; disagreements or discrepancies that arose during assessment were resolved by a fifth and sixth reviewer (EZS and CSW).

A standard checklist with 61 binary indicators ("yes" or "no") was used to assess the quality of the preparedness pandemic plans. The checklist, shown in Table 1 , is grouped across seven thematic areas: preparation (16 indicators); coordination and partnership (5 indicators); risk communication (8 indicators); surveillance and monitoring (7 indicators); prevention and containment (10 indicators); case investigation and treatment (10 indicators) and ethical consideration (5 indicators).

The indicators used to assess the African plans were developed partly from the 20 key indicators on various goals of preparedness recommended by the European Centre for Disease Prevention and Control (ECDC) and WHO Regional Office for Europe [13]. A group of 25 European countries plus Iceland and Norway through a consultative process provided feedback on the content validity of the 20 indicators [13]. Additional indicators specific to the purpose of our study and setting was pulled together by incorporating other recommendations from the WHO guidance on pandemic plan development [13, 14]. The final instrument was validated by pandemic policy planners in 7 select countries with a validity index score of not less than 0.75 .

Each plan assessed would score a maximum of 61 points for completeness across the 7 thematic areas of preparedness. We generated descriptive data, such as averages and percent of total, to gauge quality of pandemic preparedness plans. An overall plan score was calculated by assigning 1 or 0 points to each indicator. An indicator score of one is assigned to the plan if denoted by "yes" and zero for "no". The indicator was scored 1 if an item was mentioned in detail or partly described in the plan, while a score of 0 was given if the item assessed was missing or absent in the plan. All the scores were verified before entry in excel by two reviewers (EZS and CDI) prior to analysis. 
Table 1 Standardized checklist and scores for 61 indicators grouped across seven categories

\begin{tabular}{|c|c|c|c|c|}
\hline \multirow{2}{*}{\multicolumn{2}{|c|}{ INDICATORS }} & \multirow{3}{*}{$\begin{array}{l}\text { RATIONALE } \\
\text { Additional assessment guide }\end{array}$} & \multirow{2}{*}{\multicolumn{2}{|c|}{$\frac{\text { SCORES }}{\text { Number of countries }}$}} \\
\hline & & & & \\
\hline & & & \multirow[t]{2}{*}{ Yes } & \multirow[t]{2}{*}{ No } \\
\hline \multicolumn{3}{|c|}{ PREPARATION } & & \\
\hline 1 & $\begin{array}{l}\text { Does the country have a national } \\
\text { pandemic influenza plan? }\end{array}$ & Is it publicly available? & 35 & 0 \\
\hline 2 & $\begin{array}{l}\text { Does the national influenza plan } \\
\text { target human or avian influenza subtypes? }\end{array}$ & $\begin{array}{l}\text { Human influenza subtype } \\
\text { e.g. H1N1 and animal subtype e.g. H5N1 }\end{array}$ & 32 & 3 \\
\hline 3 & $\begin{array}{l}\text { Does the national pandemic } \\
\text { influenza plan meet the international } \\
\text { (WHO/IHR etc) guidance on preparedness? }\end{array}$ & $\begin{array}{l}\text { Is the plan based on the six phases } \\
\text { of planning and response? }\end{array}$ & 22 & 13 \\
\hline 4 & $\begin{array}{l}\text { Are the responsibilities and actions } \\
\text { in the plan defined phase by phase? }\end{array}$ & $\begin{array}{l}\text { This is required for capacity setting, } \\
\text { planning and command based } \\
\text { on WHO recommendations. }\end{array}$ & 21 & 14 \\
\hline 5 & $\begin{array}{l}\text { Are there local plans at } \\
\text { district and regional level? }\end{array}$ & See if are there any arrangements in place & 9 & 26 \\
\hline 6 & $\begin{array}{l}\text { Are business continuity plans } \\
\text { available across the non-health } \\
\text { sectors at national and regional } \\
\text { levels? Or are these mentioned in the plans? }\end{array}$ & $\begin{array}{l}\text { Check this among institutions (UN } \\
\text { organization and churches etc). } \\
\text { Do these plan mention how they } \\
\text { will cope with an influenza pandemic } \\
\text { and continue to provide other } \\
\text { essential health services. }\end{array}$ & 7 & 28 \\
\hline 7 & Are the plans flexible? & $\begin{array}{l}\text { Does the plan have a severity } \\
\text { index or are they able to adjust } \\
\text { whether to mild or severe } \\
\text { nature of the pandemic? }\end{array}$ & 13 & 22 \\
\hline 8 & $\begin{array}{l}\text { Do the response and inter-wave } \\
\text { planning phases have their own } \\
\text { courses of action and budgets } \\
\text { which would be implemented? }\end{array}$ & $\begin{array}{l}\text { These tasks should have financial } \\
\text { and human resource with a } \\
\text { budget provision for a year. } \\
\text { Also see question } 4\end{array}$ & 24 & 11 \\
\hline 9 & Is the plan sustainable for a longer term? & $\begin{array}{l}\text { Influenza funding and development } \\
\text { of command structures should } \\
\text { not heavily rely on external funding. }\end{array}$ & 0 & 35 \\
\hline 10 & $\begin{array}{l}\text { Does the plan have a national } \\
\text { committee(s) or advisory } \\
\text { body in place to oversee preparedness? }\end{array}$ & $\begin{array}{l}\text { Check who drafted the plan and } \\
\text { if they were part of the committee. }\end{array}$ & 32 & 3 \\
\hline 11 & $\begin{array}{l}\text { Does the plan have any assumptions } \\
\text { on which the plan is based? }\end{array}$ & $\begin{array}{l}\text { Does the plan mention the expected } \\
\text { range of cases and percentage of } \\
\text { staff off sick? Check for detailed } \\
\text { assumptions and planning principles } \\
\text { such as case scenarios that will trigger } \\
\text { responses and guide effective } \\
\text { implementation of the plan. }\end{array}$ & 14 & 21 \\
\hline 12 & $\begin{array}{l}\text { Are there a national command } \\
\text { and control structure? }\end{array}$ & $\begin{array}{l}\text { This is where data or information } \\
\text { is aggregated for the country. } \\
\text { The national command centre } \\
\text { exercise authority and can } \\
\text { designate responsibilities } \\
\text { at the local or regional levels. }\end{array}$ & 25 & 10 \\
\hline 13 & $\begin{array}{l}\text { Are there health services command } \\
\text { and control structure? }\end{array}$ & Check for hospital and clinic plans & 8 & 27 \\
\hline 14 & $\begin{array}{l}\text { Does the pandemic plan regularly } \\
\text { and systematically get tested at } \\
\text { all levels and across all sectors i.e. } \\
\text { national level health sector exercises or drills? }\end{array}$ & $\begin{array}{l}\text { Check if they carry out simulations } \\
\text { and tabletop exercises- this is } \\
\text { important because it can feedback } \\
\text { in the planning as lessons learnt. }\end{array}$ & 8 & 27 \\
\hline 15 & $\begin{array}{l}\text { Have the legal implications of } \\
\text { travel restrictions and other } \\
\text { interoperability issues been determined? }\end{array}$ & $\begin{array}{l}\text { Are there any discussions or } \\
\text { agreements on a list of issues } \\
\text { such as cross-border management } \\
\text { and quarantine? }\end{array}$ & 15 & 20 \\
\hline
\end{tabular}


Table 1 Standardized checklist and scores for 61 indicators grouped across seven categories (Continued)

\begin{tabular}{|c|c|}
\hline \multicolumn{2}{|c|}{ INDICATORS } \\
\hline 16 & $\begin{array}{l}\text { Do interventions proposed in the } \\
\text { plan have exit strategies? }\end{array}$ \\
\hline \multicolumn{2}{|c|}{ COORDINATION AND PARTNERSHIPS } \\
\hline 17 & $\begin{array}{l}\text { Are there any regional or local } \\
\text { arrangements in place on how to re }\end{array}$ \\
\hline 18 & $\begin{array}{l}\text { Are there a regional/local planning } \\
\text { and coordination structure? }\end{array}$ \\
\hline 19 & $\begin{array}{l}\text { Is the health sector well connected } \\
\text { to other sectors such as businesses } \\
\text { and civil society? }\end{array}$ \\
\hline 20 & $\begin{array}{l}\text { Are there joint cooperation and } \\
\text { partnership with the neighboring } \\
\text { countries on mutually } \\
\text { relevant influenza policy areas? }\end{array}$ \\
\hline 21 & $\begin{array}{l}\text { Does the partnership or } \\
\text { coordination involve financial } \\
\text { and technical support? }\end{array}$ \\
\hline
\end{tabular}

\section{RISK COMMUNICATION}

22 Are they a national communication strategy or is it publicly available?

23 Does the national communication strategy sufficiently stress the likely nature or duration of the pandemic, its spread, its peak and decline, nor does it sufficiently inform the public on these issues?

24 Are there any Information Education and Communication (IEC) material or IEC in place or available?

25 Are there any definitions of key target groups for specific preventive messages and protection such as health and emergency personnel within the communication plan?

26 Are there effective programmes in place to change public attitudes and perceptions about influenza?

$27 \quad$ Are churches or religious groups mentioned in the plan to help communicate preparedness messages?

28 Are there a nation-wide influenza guidance 'intranet' for health authorities respond quickly to an influenza outbreak?

RATIONALE
Additional assessment guid
What are the exit options?
When should the pandemic
be outbreak declared over?

Do plans engage local people, families and medical personnel to ensure local services are running smoothly during the pandemic period?

Check for leadership roles and among the coordinating structures.

Private and public partnership necessary to continue providing essential services such as water, energy and safe transport.

A pandemic outbreak has no borders- check how transborder problems related to pandemic influenza will be resolved or if it is a priority in the plan.

This is important for planning continuity purposes and

future responses.

Has the national communication strategy been published?

Is the national communication

strategy committed to public awareness including communicating the nature, spread, peak and decline of influenza (seasonal and pandemic?

Check if the plan use or intend to use multi-media communication i.e. newspapers, radio, $\mathrm{TV}$, posters, magazines and social networking sites such as Facebook and Twitter

Are there any public hygiene campaigns

health measures during normal

influenza seasons or outbreaks?

To avoid problems due to poor and general hygiene etc.

People are more likely to listen to

religious leaders than from health personnel.

Web reporting systems? exchange and sharing? 
Table 1 Standardized checklist and scores for 61 indicators grouped across seven categories (Continued)

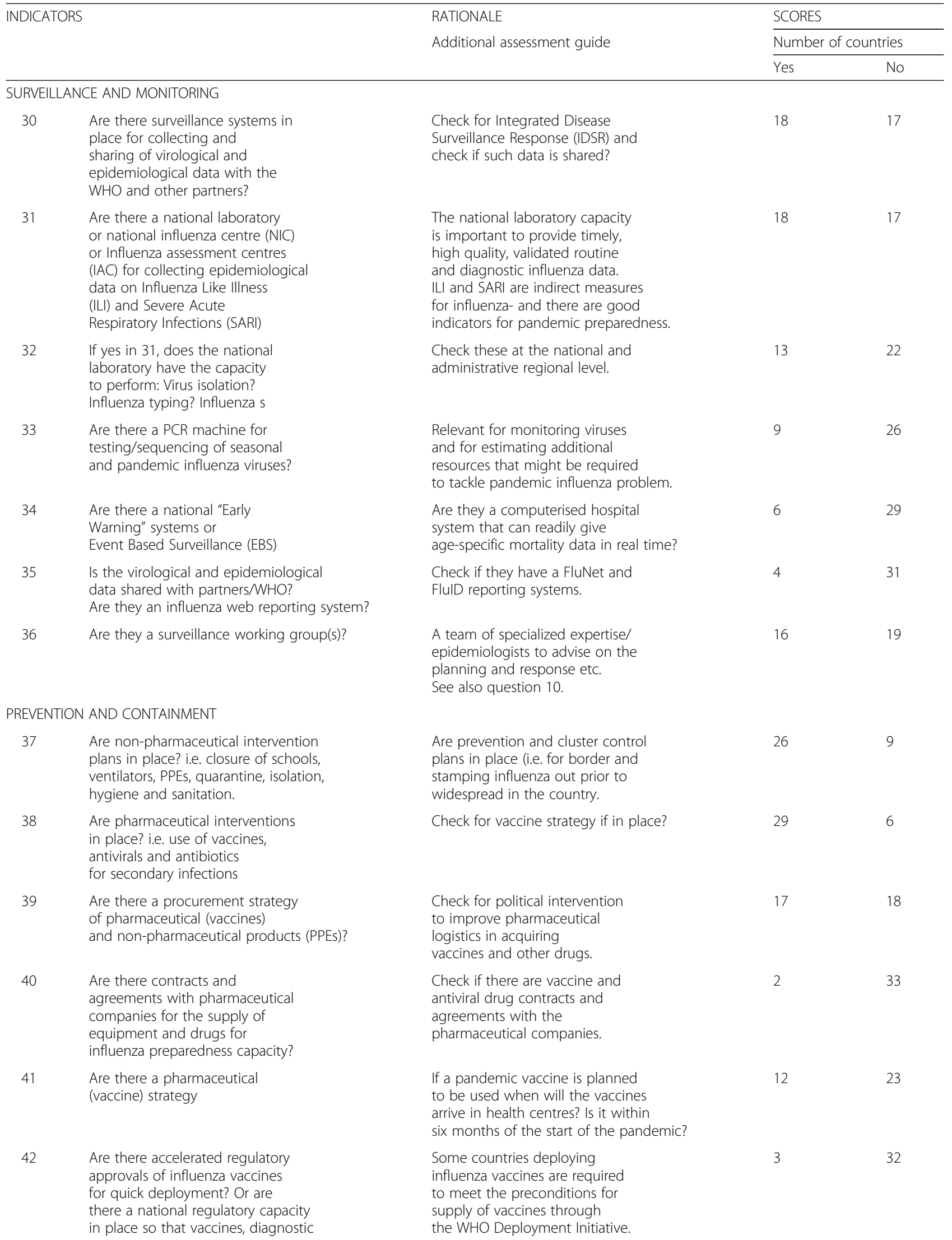


Table 1 Standardized checklist and scores for 61 indicators grouped across seven categories (Continued)

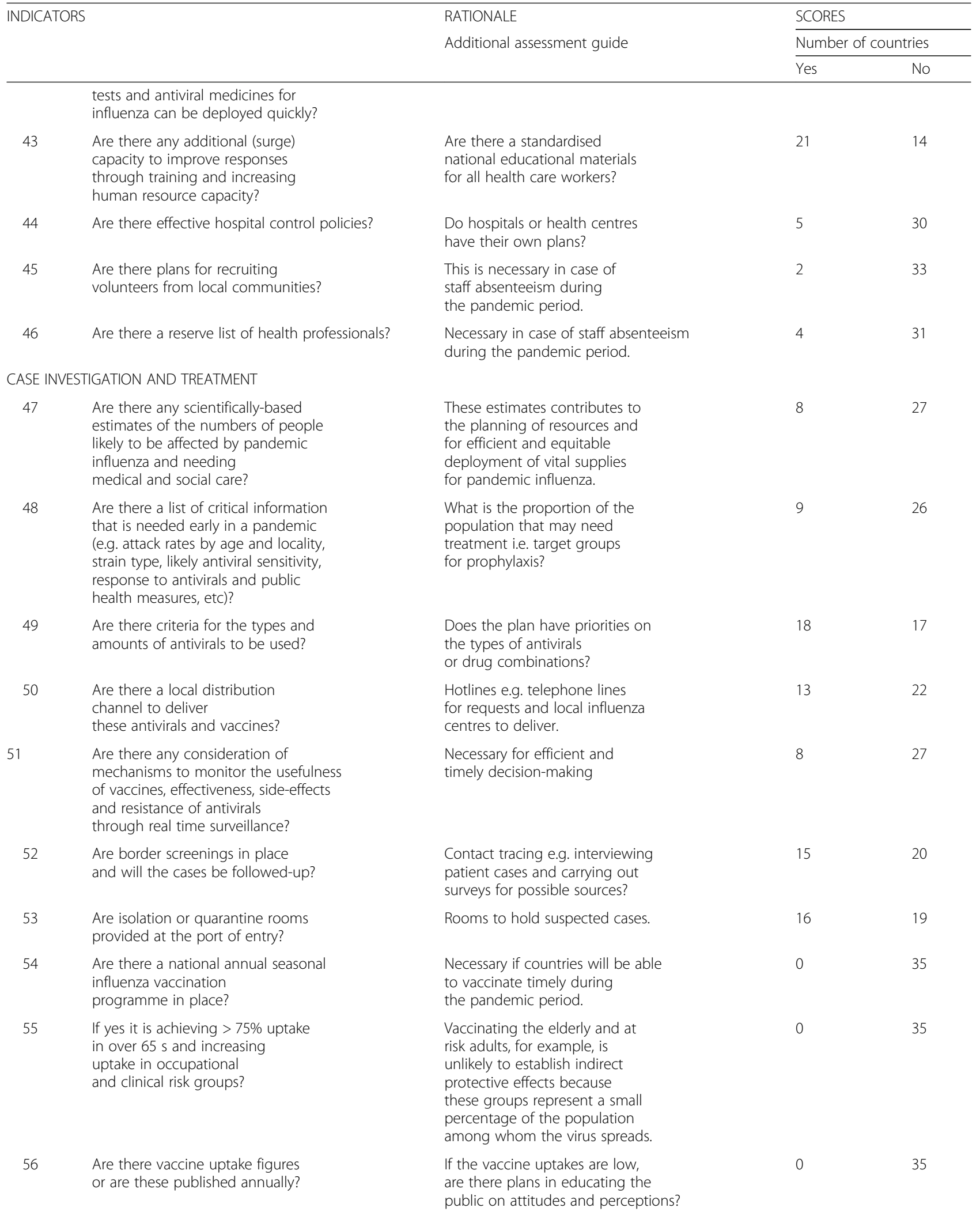


Table 1 Standardized checklist and scores for 61 indicators grouped across seven categories (Continued)

\begin{tabular}{|c|c|c|c|c|}
\hline & & \multirow{2}{*}{\multicolumn{2}{|c|}{$\frac{\text { SCORES }}{\text { Number of countries }}$}} \\
\hline \multirow{2}{*}{\multicolumn{2}{|c|}{ INDICATORS }} & & & \\
\hline & & & & No \\
\hline \multicolumn{5}{|c|}{ ETHICAL CONSIDERATIONS } \\
\hline \multirow{2}{*}{57} & Is there an ethical framework in place? & $\begin{array}{l}\text { RATIONALE } \\
\text { Additional assessment guide } \\
\text { Necessary to avoid ethical } \\
\text { problems that might arise }\end{array}$ & 1 & 34 \\
\hline & $\begin{array}{l}\text { Are there any ethical consideration } \\
\text { for appropriate use of quarantine } \\
\text { procedures, treatment of } \\
\text { patients with vaccines and antiviral drugs? }\end{array}$ & $\begin{array}{l}\text { Are there priority setting and } \\
\text { equitable access to therapeutic } \\
\text { and prophylactic measures? } \\
\text { What are the core governmental } \\
\text { responsibilities on this? }\end{array}$ & 4 & 31 \\
\hline 59 & $\begin{array}{l}\text { During implementation of the plan, } \\
\text { are there consideration to } \\
\text { balance public health and human rights? }\end{array}$ & $\begin{array}{l}\text { During a pandemic influenza } \\
\text { emergency, policymakers } \\
\text { experience tension and disputes, } \\
\text { and that they struggle to balance } \\
\text { public health decisions between } \\
\text { what is best for the } \\
\text { individual and society as a whole. }\end{array}$ & 6 & 29 \\
\hline 60 & $\begin{array}{l}\text { Are there evidence base for public } \\
\text { health measures on which } \\
\text { decisions will be based or are based? }\end{array}$ & Check in the plans if policymakers use science & 6 & 29 \\
\hline 61 & $\begin{array}{l}\text { Are there transparency, public } \\
\text { engagement and social } \\
\text { mobilization in the plan? }\end{array}$ & $\begin{array}{l}\text { Is there a list that shows the } \\
\text { beneficiaries for the interventions } \\
\text { or how the beneficiaries were } \\
\text { selected as eligible candidates } \\
\text { for the interventions or limited resources? }\end{array}$ & 7 & 28 \\
\hline
\end{tabular}

\section{Results}

Of the 47 countries in the WHO African region, 35 national pandemic plans were retrieved for assessment in this study (Table 2). We could not find plans for 12 countries- either they were not publicly available or we could not access them from the Ministry of Health in these countries upon request.

Of the plans reviewed, $60 \%$ were initially developed between 2006 (Table 2) in response to specific threats posed by the continuing spread of the avian influenza (H5N1) virus. Figure 1 shows composite scores of preparedness plans by country. The composite score for the completeness of the pandemic plans was $36 \%$ across the 35 countries. Country-specific scores on each of the thematic indicators for pandemic plan completeness varied, ranging from $5 \%$ in Côte d'Ivoire to $79 \%$ in South Africa (Fig. 1). Overall, our assessment shows that pandemic plans across the WHO African region remain inadequate, with no details on ethical considerations, case investigation and treatment. Nigeria was the only country that scored $60 \%$ across all the thematic areas of preparedness.

Figure 2 shows completeness of the preparedness plans of countries by thematic area. On average, preparation and risk communication scored $48 \%$, respectively, while coordination and partnership scored highest with an aggregate score of 49\%. Surveillance and monitoring scored $34 \%$, while prevention and containment scored 35\%. Case investigation and treatment scored $25 \%$ and ethical consideration scored the lowest of $14 \%$ across 35 countries.
Table 1 shows the scores of the assessment indicators for all thematic areas. Of the countries that had a plan available online, 33 countries planned against both human and avian influenza subtypes. Three plans- those from Algeria, Chad and Cote d'Ivoire- specifically focused on the planning for and response to avian influenza subtypes. 22 of 35 plans followed the WHO guidance on six phases of planning and response. 14 countries cited hypothetical scenarios on which the plan is based, for example, when doses of vaccines and antivirals need to be acquired to treat patients. There were 9 plans with planning initiatives at the district and regional levels, and 7 plans mentioned that they had business continuity plans across the non-health sector. We found 13 plans to be flexible with regards to the ability to quickly adjust to the severity of the pandemic. 24 countries had a budget provision for each course of action, however, all the plans were heavily dependent on external funding with no sustainable budget for their preparedness. Maximum funding for some countries, such as the Democratic Republic of Congo, was only 3 years. All but 3 countries- Algeria, Cabo Verde and Central African Republic- mentioned having a national committee or advisory body to oversee preparedness. Eight plans tested their planning for and responses through exercises and drills at the national level. There were 25 plans that had a national command and control structure, where influenza data or epidemiological information is aggregated and shared 
Table 2 Country pandemic plans assessed, year of development and last updated

\begin{tabular}{|c|c|c|c|c|c|}
\hline & Country & Year & & Country & Year \\
\hline 1 & Algeria & 2009 & 19 & Madagascar & 2006 \\
\hline 2 & Benin & $2006 / 2009$ & 20 & Malawi & 2006 \\
\hline 3 & Botswana & 2005 & 21 & Mali & 2006 \\
\hline 4 & Burkina Faso & 2005 & 22 & Mauritania & 2006 \\
\hline 5 & Cameroon & 2006 & 23 & Mauritius & 2006 \\
\hline 6 & Cabo Verde & 2006 & 24 & Mozambique & 2006 \\
\hline 7 & Central African Republic (the) & 2006 & 25 & Namibia & 2005 \\
\hline 8 & Chad & 2006 & 26 & Niger (the) & 2006 \\
\hline 9 & Comoros (the) & 2006 & 27 & Nigeria & 2007 \\
\hline 10 & Côte d'Ivoire & 2009 & 28 & Rwanda & 2006 \\
\hline 11 & Democratic Republic of the Congo (the) & 2006 & 29 & Senegal & $2005 / 2009$ \\
\hline 12 & Gabon & 2007 & 30 & Seychelles & 2007 \\
\hline 13 & Gambia (the) & $2006 / 2009$ & 31 & Sierra Leone & $2005 / 2009$ \\
\hline 14 & Ghana & $2005 / 2009$ & 32 & South Africa & $2006 / 2017$ \\
\hline 15 & Guinea & $2006 / 2009$ & 33 & Swaziland & 2006 \\
\hline 16 & Kenya & 2005 & 34 & Uganda & 2006 \\
\hline 17 & Lesotho & 2006 & 35 & United Republic of Tanzania (the) & 2007 \\
\hline 18 & Liberia & 2009 & & & \\
\hline
\end{tabular}

with regional and district levels. Hospital plans were available in 8 plans and only 4 countries had planned for exit strategies after the pandemic.

Coordination and partnership indicators showed that 24 plans engaged local people, families and medical personnel to ensure local services run smoothly during the pandemic. Another 24 plans had a functional local or regional coordination structure. 12 countries had a private and public partnership to offer essential services such as the delivery of health, safety and energy. Ten national plans had a joint cooperation and partnership with a neighbouring

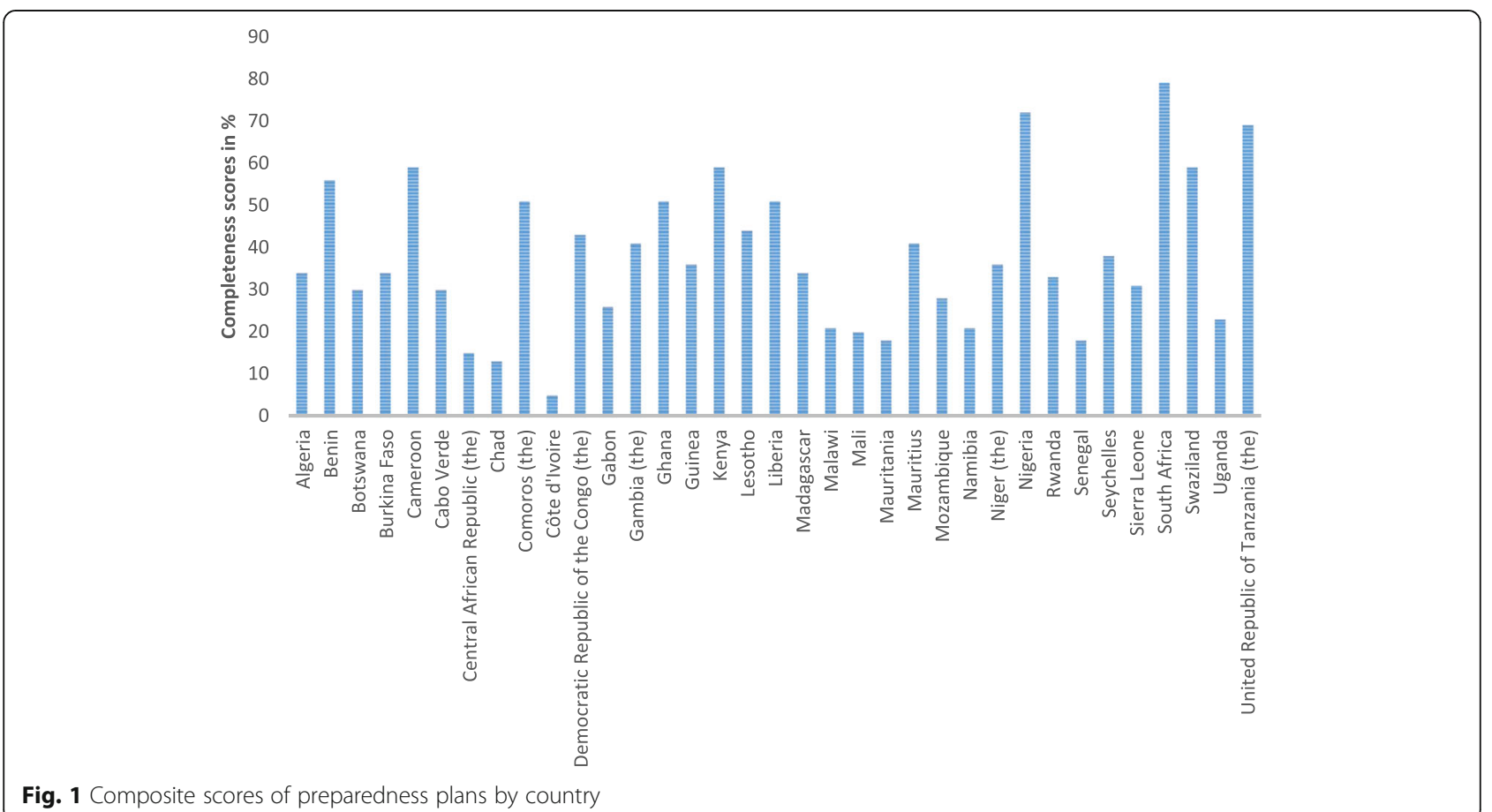




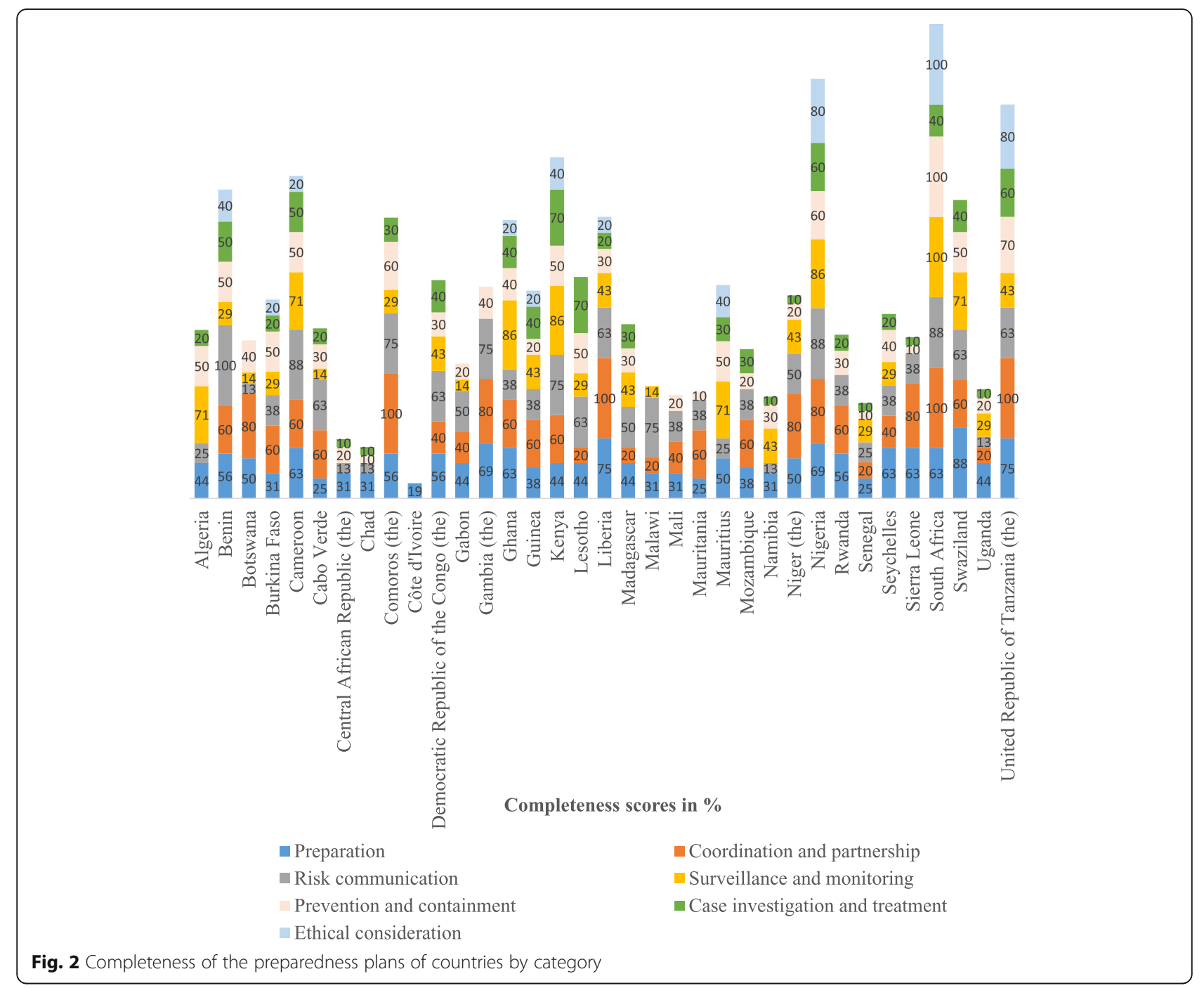

country on mutually relevant influenza policy. 16 countries held partnership and coordination that involved financial and technical support.

The risk communication indicator showed that 22 plans had a communication strategy and 11 plans mentioned the role of public awareness, including sharing information on the nature, transmission patterns, peak and decline of the influenza. 31 plans had Information, Education and Communication (IEC) materials published in multi-media such as newspapers, radio, television and social networking sites on the internet. 23 plans defined key target groups for specific preventative messages, such as public hygiene campaigns to highlight the personal public health measures during normal influenza seasons or outbreaks. 12 plans planned to avoid problems arising due to poor communication around preventative measures and general hygiene. Only 8 plans mentioned churches or religious groups to assist with communicating messages on preparedness. 9 countries had web reporting systems, such as intranet or FluNet, to speed up responses to an influenza outbreak. Information exchange among stakeholders through conferences, meetings and forums were mentioned by 17 plans.

Surveillance and monitoring are considered an important part of planning, yet 17 plans failed to mention the surveillance techniques of collecting and sharing influenza virological and epidemiological data. This is despite the presence of the integrated disease surveillance response (IDSR) system in many African countries. In these countries, there was no national influenza centre (NIC) or influenza assessment centres (IAC) for collecting epidemiological data on influenza-like illnesses and severe acute respiratory infections. Amongst those that had a laboratory, 13 countries had the capacity to perform virus isolation, typing and subtyping. 9 countries had a polymerase chain reaction (PCR) machine to test and monitor influenza circulation. Only six plans had a computerised hospital system as an early warning system 
that can readily give real-time data on influenza outbreaks. Epidemiological and virological data was shared with the WHO and other partners by 4 countriesAlgeria, Ghana, Kenya and South Africa. There were 16 plans that mentioned having a surveillance working group to give advice on surveillance and monitoring.

As part of prevention and containment of influenza, 26 countries planned for non-pharmaceutical interventions, such as closure of schools, use of ventilators, use of personal protective equipment, quarantine, isolation, hygiene and sanitation. In terms of pharmaceutical interventions, 29 plans mentioned strategies that would use vaccines, antivirals and antibiotics for treatment of secondary infections. With regards to detailed assessment of the pharmaceutical strategy, we found that 12 plans had a vaccine strategy, while 17 plans had a procurement strategy for either pharmaceutical or non-pharmaceuticals products. Only 2 plans, those from the United Republic of Tanzania and South Africa, had advanced contracts and agreements with pharmaceutical companies in place for the supply of equipment and drugs for influenza treatment. 3 plans, those from the United Republic of Tanzania, Swaziland and South Africa, had in place accelerated regulatory approval of influenza products for quick deployment. Additional surge capacity to improve responses through training and human resources was available in 21 of the plans. The hospital plans were available in 5 plans and 2 plans (Algeria and South Africa) mentioned the need for recruiting volunteers from the local community. In terms of human resource, 4 plans suggested recruitment of staff from a reserve list of health professionals.

In the category of case investigation and treatment, 8 plans had science based influenza planning assumptions for efficient and equitable deployment of vital supplies against influenza. As part of planning, 9 plans included critical information such as attack rates by age and locality, strain type, antiviral sensitivity or who to target for prophylaxis. 18 plans mentioned the criteria and types of antivirals to use in an event of an outbreak. The most commonly mentioned antivirals were zanamivir and oseltamivir. About 13 plans mentioned that they will deliver these antivirals through local distribution channels, including the use of telephone line and local influenza centres. Mechanisms to monitor the effectiveness, side effects and resistance of vaccines or antivirals were considered in 8 plans through real time surveillance. Plans to screen cases at the borders and follow up cases were indicated in 15 plans, while isolation or the provision of rooms at the border entry were only mentioned in 16 plans. No plan reported the intention to vaccinate seasonally (i.e. achieving $>75$ uptake in the elderly population), nor published any vaccination figures despite indicating that they will vaccinate its population.
Ethical consideration was inadequately reported in most plans, with only 1 plan (South Africa) having completely reported to have an ethical framework in place. 4 plans considered an ethically appropriate use of quarantine procedures, fair allocation of treatment and limited resources such as vaccines. 6 plans considered how to balance between public health and human rights interests if they came into conflict. 7 of the plans indicated the need for transparency in decision making, for example, how eligible beneficiaries would be selected to receive scarce interventions.

\section{Discussion}

Preparing for a response towards a pandemic extends beyond the development of the plan to include an implementation plan that lays out how the goals of the plan match available resources, tasks and responsibilities, to meet the needs of the population affected by the pandemic outcomes. Preparedness plans are crucial to build frameworks for emergency response, thereby providing countries with the opportunity to plan, strategise and mobilise human and capital resources before a pandemic occurs. Adequate and thorough plans ensure that countries can respond immediately when a pandemic is declared.

While our study showed that the majority of the African countries have a plan (74\%), the majority of these plans are inadequate, with many tasks necessary to address pandemic threats of the twenty-first century remains unmet. This finding corresponds to studies that evaluated preparedness plans and responses to the 2009 H1N1 pandemic in Ghana and Malawi, where such plans were found to be weak and unable to elicit the most desired responses during the pandemic $[15,16]$. The findings of this study also concur with an evaluation done by Ortu et al. (2008), who reported that the plans lacked operational clarity and focus of the planning objectives [17].

Our findings indicate that the majority of plans have not been updated over time, despite the lessons offered by the $2009 \mathrm{H} 1 \mathrm{~N} 1$ pandemic. Our findings also show that only 7 of the assessed countries in Africa updated or revised their plans periodically to incorporate the changing circumstances and lessons gathered from the 2009 pandemic. For instance, South Africa is one of the countries with consistent updates to its plan, with a recently developed five-year national influenza policy and strategic plan outlining a comprehensive approach to influenza prevention and control [18]. A plan needs to be a living document, periodically adapted as new information on the influenza becomes available and thus ready to provide a guide to the protocols, procedures, and division of responsibilities in emergency response [12]. 
Results of our study also suggest that many countries did not consider the proposed phases of preparedness to respond more efficiently to the influenza pandemic. This is despite the fact that the WHO has provided an up-to-date evidence-based guidance to support countries to develop and revise pandemic preparedness plans. Recently, the WHO published an updated pandemic influenza preparedness checklist to help Members States build capacity for pandemic response [14]. However, our review highlights how many countries in the WHO African region are yet to incorporate these guidelines despite the need to improve existing plans.

Our study also shows that many countries do not have business continuity plans across the non-health sector at the subnational level. An influenza pandemic is an unpredictable event that can create a major management crisis of unprecedented scale and cost. High absence of workers from duty could drastically interrupt the functioning of critical infrastructure, such as services essential to health, technology and communication networks, economic wellbeing, safety and security. Due to the disruptive nature of the pandemic to social services and the economy, development of business continuity plans embedded within the national plan is critical for an effective country response that minimizes the financial consequences on all businesses of all sizes and types [19].

In our study, we observed that only a few national plans engaged with specific sectors, such as education, hospitals, industry and local community. It is useful for plans to make meaningful arrangements at the local level, because this is where the burden of the disease occurs and is largely felt. In addition, in the aftermath of the pandemic, the local level is where the plans can continue to be implemented. Interestingly, apart from local coordination, we found that few countries had joint cooperation and partnership from non-health sector in preparedness, thus making interoperability and integration of planning efforts and services impossible. The purpose of planning and involving cooperation and partnership at all levels is to support and promptly restore key routines and functions prone to disruptions in our societies. Even a well-designed and motivated plan without partnerships will fall short in managing the crisis, and will struggle to guide recovery effectively if it does not extend responsibilities and command across local government, stakeholders and international partners.

Although surveillance is considered one of the most crucial planning activities, in this study we found that half of the plans did not incorporate the techniques of collecting virological and epidemiological data for the early detection of the virus causing an epidemic. The majority of the surveillance plans in place were weak. The role of surveillance techniques and systems is to send early signals of an imminent influenza outbreak in the human and animal population, and yield knowledge for treatment, prevention and control of influenza [20]. For many plans, it was impossible to fulfill these tasks in the absence of laboratories and equipment, such as PCR machines to perform virus typing and subtyping. According to the IHRs, all countries are mandated to monitor and rapidly report disease outbreaks that pose a threat to other countries [11]. Apart from alerting respective countries about the nature of the influenza virus in circulation, understanding disease virology can be useful for vaccine production. However, without the necessary tools to conduct surveillance, public health interventions to reduce influenza pandemic are jeopardized.

An interesting finding from this study was that 26 countries proposed to use non-pharmaceutical interventions (case isolation, restricting children's visits to hospitals, workplace closure etc.), while nearly all indicated the use of pharmaceutical interventions i.e. vaccines, antivirals and antibiotics for treatment of secondary infections. Although vaccines are a primary strategy for preventing and mitigating influenza outbreaks, many plans do not specify whether vaccines will be acquired on time. Since influenza viruses change overtime due to the antigenic shifts and drifts, it is difficult to produce an appropriate and effective influenza vaccine for unknown subtypes [20].

As such, during the first few months of a pandemic influenza, vaccination will not be a primary intervention strategy. The time during which there are no vaccines, combined approaches of non-pharmaceutical interventions can minimize morbidity and mortality due to influenza pandemic. There is no point in making arrangements to use vaccines (including other treatments products and materials) when these products will not be available or are unlikely to be supplied within a useful time frame to mitigate the disease. If specific arrangements are proposed, then plans should take into account both the limitations and the capabilities of the responses.

Most importantly, although often forgotten in the majority of the preparedness plans is the need for ethical considerations. Our study indicates that, with the exception of one plan (South Africa), no other plans reported having an ethical framework in place. There is an expectation that during a pandemic influenza outbreak, ethical issues will arise due to conflicting interests between civil liberties (i.e. violation of human rights) and population health (i.e. greatest good for the greatest number) [20]. In the absence of an ethical plan, it is difficult to respond appropriately to ethical dilemmas and this can constitute a threat to preparedness and response. We propose that all countries develop an ethical framework that can be used to address ethical problems such as these of rationing limited vaccines or failure by 
health care-workers to work on the bedside during the pandemic.

Our study has several limitations. Our analysis was based on pandemic plans that are freely available online and thus it is possible that some of these plans would have been updated and the revised versions of the plans not yet published. Our study may therefore be a misrepresentation of the preparedness. We were only able to assess written materials in the protocols, yet crisis preparedness extends beyond these documents to include the ability to perform within the means using the necessary and available tools and infrastructure. Thus, we are not suggesting that countries that scored high in the completeness scores for preparedness will do the same in real crisis situations. However, for country preparedness to be truly effective at preventing and responding to influenza, plans must be created and drills and exercises conducted to ensure they prevent and address influenza pandemic. Another limitation involved the process of scoring the plans without a weighting scale, which may have introduced bias especially among those indicators that fell between 1 and 0 . A further methodological limitation involved scoring the same plan twice i.e. the initial draft and updated version. As such, countries with more than one national plan may have been more likely to achieve a higher score, thus skewing the scores for those plans. Finally, we used google translation software to translate French plans into English and thus some words may have been lost in translation. Most importantly, we excluded one French written plan (Togo) from the analysis because the format of the plan made it unable to be translated.

\section{Conclusion}

Based on our assessment of the plans, we found preparedness plans to be weak therefore, these plans must address the gaps identified in this study. We recommend improving the overall goals in preparedness and these are achievable through drills, simulations and tabletop exercises.

\section{Abbreviations}

EBS: Event based surveillance; ECDC: European centre for disease prevention and control; H: Hemagglutinin; HPAl: Highly pathogenic avian influenza; IAC: Influenza assessment centres; IDSR: Integrated disease surveillance response; IEC: Information, education and communication; IHR: International health regulations; ILI: Influenza like illness; N: Neuraminidase; NIC: National influenza centre; PCR: Polymerase chain reaction; SARI: Severe acute respiratory infections; WHO: World Health Organization

\section{Acknowledgements}

The authors would like to thank Dr. Sara Cooper for proof reading the article and Ms. Lindi Mathebula for making the graphs visible.

\section{Funding}

We did not receive funding for this study.

\section{Availability of data and materials}

The datasets used and/or analysed during the current study are available from the corresponding author on reasonable request.

\section{Authors' contributions \\ EZS conceived the study. EZS, AJ, CDI, TK, CJl and CSW collected the data and performed the analysis. EZS wrote the manuscript and all the authors contributed to shaping of the argument of the article, and participated in the manuscript writing. All the authors read and approved the final manuscript.}

\section{Ethics approval and consent to participate}

We analyzed publicly available data as such no formal ethical review is required.

\section{Consent for publication}

Not applicable because there are no individual details, images and videos in this study.

\section{Competing interests}

The authors declare that they have no competing interests.

\section{Publisher's Note}

Springer Nature remains neutral with regard to jurisdictional claims in published maps and institutional affiliations.

\section{Author details}

${ }^{1}$ Cochrane South Africa, South African Medical Research Council, Box 19070, Cape Town, PO 7505, South Africa. ${ }^{2}$ Vaccines for Africa Initiative, Division of Medical Microbiology and Institute of Infectious Disease and Molecular Medicine, University of Cape Town, Cape Town, South Africa. ${ }^{3}$ Division of Health Systems and Public Health, Department of Global Health, Faculty of Medicine and Health Sciences, Stellenbosch University, Cape Town, South Africa. ${ }^{4}$ Department of Biochemistry and Microbiology, University of Fort Hare, Alice, South Africa. ${ }^{5}$ Division of Epidemiology and Biostatistics, School of Public Health and Family Medicine, University of Cape Town, Cape Town, South Africa. ${ }^{6}$ Centre for Evidence-Based Health Care, Division of Epidemiology and Biostatistics, Department of Global Health, Faculty of Medicine and Health Sciences, Stellenbosch University, Cape Town, South Africa.

Received: 23 May 2018 Accepted: 31 October 2018

Published online: 14 November 2018

\section{References}

1. Sleman SS. How influenza a causes "epidemics and pandemics" among the population: novel targets for anti-influenza molecules. Biom Biostat Int J. 2018;7(5):452-5. https://doi.org/10.15406/bbij.2018.07.00246.

2. Tognotti E. Influenza pandemics: A historical retrospect. The Journal of Infection in Developing Countries. 2009;3(05):331-4.

3. Taubenberger JK, Morens DM. 1918 influenza: the mother of all pandemics. Emerg Infect Dis. 2006;12(1):15-22.

4. Johnson NP, Mueller J. Updating the accounts: global mortality of the 19181920" Spanish" influenza pandemic. Bull Hist Med. 2002;76(1):105-15.

5. Nicholson KG, Wood JM, Wood JM, Zambon M. Influenza. Lancet. 2003; 362(9397):1733-45.

6. World Health Organization (WHO). Pandemic (H1N1) 2009 - update 112 [updated May 23, 2010]. Available from: http://www.who.int/csr/don/2010_ 08_06/en/

7. Peiris JS, de Jong MD, Guan Y. Avian influenza virus (H5N1): a threat to human health. Clin Microbiol Rev. 2007;20(2):243-67.

8. World Health Organization (WHO). Influenza Pandemic Plan - The role of WHO and Guidelines for National and Regional Planning, Geneva, Switzerland, 1999. Available from: http://www.who.int/iris/handle/10665/ 66155.

9. World Health Organization (WHO). WHO global influenza preparedness plan the role of WHO and recommendations for national measures before and during pandemics. 2005. Available from: http://www.who.int/csr/resources/ publications/influenza/WHO_CDS_CSR_GIP_2005_5.pdf. 
10. World Health Organization (WHO). Global Influenza Programme: Pandemic influenza preparedness and response: a WHO guidance document: World Health Organization; 2009.

11. World Health Organization (WHO). International health regulations (2005). In: World Health Organization; 2008.

12. Alexander D: Disaster and emergency planning for preparedness, response, and recovery. In Edited by Anonymous Oxford University Press; 2015.

13. European Centre for Disease Prev Control (ECDP). Guide to revision of national pandemic influenza preparedness plans - Lessons learned from the 2009 A(H1N1) pandemic. Stockholm: ECDC; 2017. Available from: [https:// ecdc.europa.eu/sites/portal/files/documents/Guide-to-pandemicpreparedness-revised.pdf].

14. World Health Organization: Essential steps for developing or updating a national pandemic influenza preparedness plan 2018.

15. Sambala EZ, Manderson L. Anticipation and response: pandemic influenza in Malawi. 2009 Global health action. 2017;10(1):1341225.

16. Sambala EZ, Manderson L. Policy perspectives on post pandemic influenza vaccination in Ghana and Malawi. BMC Public Health. 2017;17(1):227.

17. Ortu G, Mounier-Jack S, Coker R. Pandemic influenza preparedness in Africa is a profound challenge for an already distressed region: analysis of national preparedness plans. Health Policy Plan. 2008;23(3):161-9.

18. National Department of Health. Republic of South Africa: National Influenza Policy and Strategic Plan 2017 to 2021. National Department of Health; 2017:1-32.

19. Rebmann T, Wang J, Swick Z, Reddick D, delRosario JL. Business continuity and pandemic preparedness: US health care versus non-health care agencies. Am J Infect Control. 2013;41(4):e27-33.

20. Sambala EZ: Ethics of planning for, and responding to, pandemic influenza in Sub Saharan Africa: qualitative study. PhD diss., University of Nottingham 2014. http://eprints.nottingham.ac.uk/14475/.

Ready to submit your research? Choose BMC and benefit from:

- fast, convenient online submission

- thorough peer review by experienced researchers in your field

- rapid publication on acceptance

- support for research data, including large and complex data types

- gold Open Access which fosters wider collaboration and increased citations

- maximum visibility for your research: over $100 \mathrm{M}$ website views per year

At $\mathrm{BMC}$, research is always in progress.

Learn more biomedcentral.com/submissions 